\title{
Hacia un marco teórico y analítico del poder naval. Contribución doctrinaria al desarrollo de la Armada de México
}

DOI: $10.32870 /$ mycp.v12i35.327

Marcos Pablo Moloeznik ${ }^{1}$

Dedicado a Íñigo Guevara, experto en sistemas de arma y joven promesa mexicana en el campo de la defensa nacional

\section{Resumen}

México es un país bi-oceánico con un extenso litoral marítimo, pero con un tradicional desinterés político y social en desarrollar una armada capaz de preservar sus derechos y riquezas en las zonas contigua y económica exclusiva, así como de enfrentar a la delincuencia organizada en la mar. De ahí la imperiosa necesidad de abrir un debate sobre el presente y futuro del poder naval, a partir de un riguroso marco teórico y analítico. Dicho en otras palabras, de contribuir, doctrinariamente, a generar capacidades mínimas para ejercer la soberanía efectiva sobre lo que el Derecho del Mar le reconoce a México, por el solo hecho de ser un Estado ribereño.

Palabras clave: intereses marítimos, poder naval, poder marítimo, armada, reforma naval, reforma del Estado, México.

1. Profesor-investigador del Departamento de Estudios Políticos, Centro Universitario de Ciencias Sociales y Humanidades, Universidad de Guadalajara. ORCID http://orcid.org/0000-0002-4078-9451 


\section{Introducción}

México es un país marítimo o ribereño, al que el Derecho del Mar, rama del Derecho Internacional Público, le reconoce: soberanía plena sobre las 12 millas de aguas territoriales, medidas normalmente desde la línea de bajamar a lo largo de la costa; poder de policía, con la potestad de sancionar infracciones aduanales, fiscales, migratorias, sanitaria y fitosanitarias, entre otras, en las 12 millas de zona contigua al mar territorial; y el derecho exclusivo de explorar y explotar los recursos renovables y no renovables, en la zona económica exclusiva, que se extiende desde el límite externo del mar territorial hasta las 200 millas (Organización de Naciones Unidas, 1982).

Además, para la Secretaría de Marina (Secretaría de Marina, 2009 b):

[...] México, por su configuración geográfica, tiene vocación marítima porque posee largos litorales bañados por el Océano Pacífico, incluyendo el Mar de Cortés; así como por el seno del Golfo de México y el Mar Caribe. Ambos, integrantes de la costa americana del Océano Atlántico que suman 10,740.9 kilómetros; cuyo significado es que México cuenta con uno de los 10 litorales más largos del mundo, con ventajas comparativas, como la zona tropical con toda la riqueza y biodiversidad acuática que ello significa [...]

Tampoco deben soslayarse los 2'946,825 $\mathrm{km}^{2}$ de superficie marina, en la que México ejerce libre soberanía para explorar, explotar, conservar y administrar los recursos vivos y no vivos de los fondos marinos, incluidos los del subsuelo y del agua suprayacente. A lo que se suma el derecho exclusivo y de jurisdicción para utilizar islas arrecifales, establecer estructuras artificiales (plataformas petroleras) e imple-

La naturaleza del poder naval mexicano se puede definir como de policía marítima, guardacostas o prefectura mentar el desarrollo de actividades científicas, además de preservar el medio marino y eliminar los agentes contaminantes (Aguayo y Trápaga, 1996).

Sin embargo, esta importante fuente de riqueza y comunicaciones y los derechos conferidos por la Convención de las Naciones Unidas sobre el Derecho del Mar, por el estatus de estado ribereño (Organización de las Naciones Unidas, 1982), no guardan correspondencia con su poder 
naval, al considerarse a la marina de guerra mexicana como costera, modesta y anticuada (Moloeznik, 2005: 203-206).

Dicho en otras palabras, la Armada de México carece de las capacidades mínimas que requiere una marina de guerra, a la cual el soberano le asigna un conjunto de misiones en tiempos de paz y de guerra y que pueden sintetizarse en el ejercicio efectivo de la soberanía en los espacios marítimos. Esto es, la naturaleza del poder naval mexicano se puede definir como de policía marítima, guardacostas o prefectura, cuyos medios sólo le permiten un control real sobre el mar territorial y parcial sobre la zona contigua, como se intenta demostrar más adelante.

De aquí surge la imperiosa necesidad de sentar las bases doctrinarias (marco teórico y analítico), para el desarrollo de la Armada de México, tema central de la presente contribución. De lo que se trata es de incentivar el debate sobre el necesario proceso de reforma naval, que debería ocupar un lugar destacado en la agenda de reforma del Estado mexicano.

\section{Hacia un marco teórico y analítico del poder naval (Guitton, 1972; Gorshkov, 1980; Lacaste, 1981; Simpson, 1983; Tangredi, 2002; y Vego, 2008).}

Tratándose de Estados cuyas costas son bañadas por el mar, en primer lugar se debería abrevar en los siguientes conceptos básicos:

Intereses marítimos: constituyen aquellos aspectos relativos a la seguridad y desarrollo del Estado-nación, vinculados con el mar. Bajo esta concepción, resulta de importancia capital la denominada conciencia marítima del pueblo, a la sazón, savia que nutre a estos intereses; en otras palabras, el intangible de la voluntad nacional, de pueblo y gobierno, de utilizar los beneficios que brinda el mar como verdadero motor que dinamiza y potencia a los intereses marítimos.

Los mismos suelen agruparse en tres amplios aspectos:

- Vías de comunicación, para tránsito de mercancías y personas (puertos, industria naval, meteorología).

- Explotación de riquezas del mar y de su fondo - suelo y subsuelo- (pesca, algas, nódulos polimetálicos, hidrocarburos, energía/mareas).

- Empleo del mar en el orden político internacional. 
En tanto que el poder naval tiene su razón de ser en el respaldo de esos intereses marítimos: no tendría sentido contar con una Armada de no existir intereses marítimos; $y$, por otra parte, resultaría muy poco sensato no disponer de un determinado poder naval capaz de respaldar los intereses marítimos de la nación (Pertusio, 1990: 19 y 20), lo que impone una revisión de la segunda concepción.

Poder naval: expresión militar de un Estado-nación en el mar; constituye el respaldo de los intereses marítimos.

Poder naval $=$ Armada $=$ Marina de Guerra + Bases.

En principio, se ve plasmado en la Armada o marina de guerra; a la sazón, el servicio armado por excelencia encargado de la defensa de un país por mar; o, lo que es lo mismo, expresión militar en el mar. Para ello opera con destructores, fragatas, corbetas, buques balizadores, remolcadores, buques de asalto anfibio y, unas pocas, con portaaviones. Además, poseen aviación naval, infantería de marina utilizada para operaciones anfibias, medios de comunicaciones, de entrenamiento, más personal, tanto militar como civil.

Aunque los elementos del poder naval no están limitados a naves de combate, armas y personal adiestrado, sino que incluyen los establecimientos costeros, bases bien ubicadas, tráfico comercial y alianzas internacionales ventajosas. La capacidad de una nación de ejercer el poder naval también se basa en el carácter y cantidad de su población y en la naturaleza de su gobierno, el vigor de su economía, su eficiencia industrial, el desarrollo de sus comunicaciones interiores, la calidad y cantidad de sus puertos, la extensión de su costa y la ubicación de su territorio, bases y colonias, respecto a las comunicaciones por mar (Potter y Nimitz, 1960: VII).

El poder naval, en su más amplia acepción, comprende no solamente su fuerza militar a flote - por quien se rige y gobierna el mar o una parte de él, mediante la acción de las armas-, sino también su flota mercante y comercio, fuentes naturales de donde únicamente puede nacer y sostenerse aquél (Pertusio, 1990: 40).

Esto es magistralmente interpretado por Alfred Thayer Mahan (18401914) (Sprout, 1968: 219 y ss.) ${ }^{2}$ en su obra "La influencia del poder naval en

2. Nadie como Alfred Thayer Mahan ha influido tan directa y profundamente en la teoría del poder naval y de la estrategia naval. Aceleró y encaminó una revolución en la política naval norteamericana pendiente desde largo tiempo atrás; proporciono un fundamento teórico a 
la historia", publicada en 1890 en el Naval War College de Estados Unidos, en cuyo prefacio se puede leer (Mahan, 1946: 13): "Puede decirse, como regla general, que el uso y control del mar es y ha sido siempre un gran factor en la historia del mundo" (Mahan, 1980: 13)

Por lo tanto (Mahan, 1946: 17):

La historia del poder naval es, en su mayor parte, aunque no de un modo exclusivo, la narración de una serie de luchas entre las naciones, de rivalidades mutuas y de violencias, frecuentemente terminadas en guerra. Mucho antes de que se descubrieran los verdaderos principios que rigen el crecimiento y prosperidad del comercio marítimo, se había visto ya con toda claridad la profunda influencia que éste ejerce sobre la riqueza y el poderío de los países [...] El choque de intereses, los odios nacidos de las tentativas violentas hechas para conseguir la mayor parte de las ventajas comerciales o para apoderarse de distintas regiones con las que convenía establecer comercio, condujeron muchas veces a la guerra. Por otra parte, las guerras originadas por causas distintas han sido modificadas grandemente, tanto en su modo de ser como en sus resultados, por el dominio del mar [...].

Las principales condiciones que afectan al poder naval de las naciones, es el resultado de ciertas características que los británicos poseían (Mahan, 1980: 32 y ss.):

I. Posición geográfica (potencia insular en el medio de líneas marítimas); II. Configuración física incluyendo en ésta - y en su relación con ella-, los productos naturales y el clima (posesión de puertos aptos); III. Extensión territorial (suficientemente grande para suministrar la riqueza material necesaria, pero no tanto como para ser indefendible); IV. Población o número de habitantes (suficiente para proveer tripulaciones); v. Carácter del pueblo (grado de conciencia marítima); vi. Carácter del gobierno, incluyendo las instituciones nacionales que haya (voluntad de apoyar una política naval progresiva).

Dicho en otros términos, el poder naval consiste en la influencia ejercida por una combinación de fuerzas militares (principalmente navales, pero actuando en conjunto con tierra y aire) y fuerzas no militares. Por lo tanto, una estrategia marítima hace referencia a los métodos mediante los cuales los

la decisión de Gran Bretaña de seguir siendo la potencia naval dominante, y dio un impulso a la evolución naval alemana realizada por Guillermo II y el Almirante Alfred von Tirpitz. De un modo u otro, sus escritos afectaron el carácter del pensamiento naval de Francia, Italia, Rusia, Japón y de potencias menos importantes. Fue un historiador de renombre y, al mismo tiempo, un propagandista del renacimiento del imperialismo. 
países tratan de mantener o incrementar su poder naval, y al modo en que intentan utilizarlo para lograr sus objetivos deseados, en tiempo de paz y de conflicto armado (Till et al., 1984: 31).

El pionero del pensamiento naval hace hincapié en la siguiente idea-fuerza (Mahan, 1946: 534):

Del único modo como puede ser peligroso y quizás fatal el ataque al comercio es con el dominio militar del mar, con la ocupación prolongada de los centros comerciales que posean importancia estratégica; y semejante dominio sólo puede adquirirse por medio de una Marina poderosa utilizada para combatir y vencer al enemigo [...]

De lo que se trata es del uso y negación, es decir, la capacidad de utilizar el mar con el propósito de hacer la guerra e impedir que el enemigo haga lo mismo. Esto es, el denominado control del mar; entendiéndose por tal el "dominio del mar", a saber: aquellas actividades dirigidas tanto al uso propiamente del mar como a impedir su uso por parte del enemigo. O sea, la capacidad de usar las líneas de comunicaciones en el mar para propósitos militares y civiles, y negar dicho uso al enemigo (Till et al., 1984: 33 y 58).

De acuerdo con otro reconocido historiador y teórico de la guerra naval, Sir Julian Corbett (1854-1922) (Navy Records, 2009), el estado natural de los mares es ser indomables. Aunque pueda uno controlar algunos de ellos, no puede ni necesita dominarlos a todos; sólo necesita controlar las áreas que son esenciales para los fines de la guerra (v. gr. control de determinados estrechos). Este pensador sostiene que la guerra naval es mucho más que la destrucción de la flota enemiga. De ahí se desprende que toda Armada tenga que aprender a usar su amplio espectro de capacidades para aplicar presiones que deba soportar el enemigo y que contribuyan al esfuerzo del Ejército, además de la consolidación de los objetivos políticos por los cuales se libra la guerra; por lo que destaca la importancia de las operaciones conjuntas y el adecuado equilibrio en el empleo correcto de Ejércitos y Marinas (Ranft, 1984: 57).

Surge así el principio de selectividad: para que los convoyes naveguen por los mares no es necesario acabar con todas las naves corsarias del enemigo que surcan los mares, ya sean submarinos o naves de superficie; basta con controlar la zona por la que los convoyes vayan a navegar. Si hacen esto, podrán llamar la atención y atraer hacia el convoy a aquellos submarinos que se quieran destruir (Cfr. Howard, 1996). 
Tampoco debe pasarse por alto que el dominio de los mares constituye tan sólo un medio al servicio del objetivo político de la guerra. Además, la estrategia naval (así como la aérea) debe interactuar, de manera continua, con la estrategia terrestre. En otras palabras, el dominio de los mares debe ejercerse a fin de influir en las decisiones que solamente pueden ser adoptadas por personas con los pies bien puestos en la tierra, ya sea matándolos de hambre o desembarcando tropas (Howard, 1996).

Cabe destacar que el poder naval es el más completo componente del factor militar, ya que posee cuatro dimensiones: marítima o naval propiamente dicha; aérea; submarina y terrestre; las que se traducen en unidades de superficie (buques); unidades aeronavales (aviones y helicópteros, basados en buques y en tierra); unidades submarinas; y unidades anfibias (infantería de marina), respectivamente.

La existencia de intereses marítimos, obliga al Estado ribereño a hacer uso del mar. Las Armadas siempre han existido para asegurar al Estado poder hacer uso del mar en beneficio propio, brindando además la capacidad suficiente para impedir que los demás lo usen en detrimento de esos fines (Booth, 1980: 20).

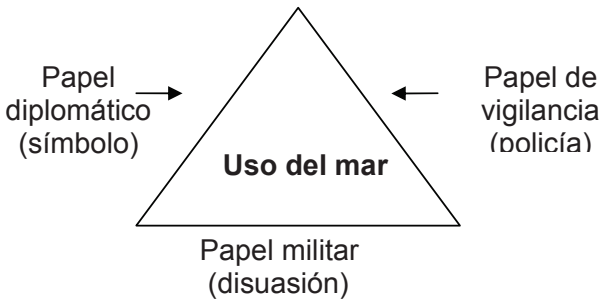

Fuente: elaborado con base en Booth (1980: 20), figura sobre "Las funciones de la Armada".

El papel militar constituye la base del triángulo, pues la esencia de las Armadas es su naturaleza militar: la Armada de México, por ejemplo, se concibe como una institución militar nacional, de carácter permanente, cuya misión es emplear el Poder Naval de la Federación para la defensa exterior y coadyuvar en la seguridad interior del país (Secretaría de Marina, 2009 d).

La violencia potencial o efectiva es la moneda de cambio; la capacidad de una Armada para usar la fuerza o amenazar con su uso, es lo que da significado a sus otros modos de acción. La amenaza militar, la capacidad potencial y efectiva del ejercicio de la violencia — la base del triángulo—, se erige en uno 
de los tres roles destinados al poder naval. Por su parte, la disuasión requiere la concurrencia de tres factores: las unidades, las dotaciones y el poder político; debiendo evidenciar este último una clara vocación de emplear a su Armada y en última instancia empeñarla en combate cuando las circunstancias lo requieran (Pertusio, 1990: 75 y 79).

Recapitulando, las Armadas existen porque los países con litoral marítimo tienen intereses que proteger en el mar; son un instrumento al servicio del poder político de la nación; actúan en un vasto escenario de fronteras no bien definidas y con posibilidad de proyectarse a enormes espacios no sujetos a jurisdicción alguna, por lo que se reconoce que la proyección del poder naval es, en definitiva, una expresión del poder nacional.

Poder marítimo: expresión amplia de capacidad de una nación para hacer uso del mar, en su acción de proyección política, económica y cultural (George, 1980).

Poder naval + Intereses marítimos = Poder marítimo

La ecuación del poder marítimo comprende un conjunto de factores que condicionan el logro de los objetivos políticos en el campo de los intereses marítimos; intereses cuya determinación, desarrollo o seguridad se hallan vinculados a la utilización del mar (Blanco Núñez, 1996: 1):

- La conciencia marítima o carácter nacional, entendido como la comprensión del grado en que se depende del mar para la vida y la seguridad.

- El complejo geomarítimo, que viene dado por la situación geográfica, la configuración física y la marina mercante (comercial, pesquera y deportiva).

- La infraestructura explotadora de los recursos del mar.

- El potencial económico.

- El poder naval, conformado por buques y bases.

En este marco y a lo largo de su devenir histórico, las Armadas, concebidas para salvaguardar los intereses marítimos nacionales, han tenido y tienen que cumplir con un conjunto de misiones establecidas por el poder político. 


\section{Viejas y nuevas misiones para las Armadas del siglo XXI (Till et al., 1984; Tangredi, 2002: 4-21; Hagedorn Hitschfeld, 2008: 229-232; Vego, 2008: 8-17)}

Las Armadas y la estrategia marítima se encuentran gobernadas por el mundo real. Una de las principales enseñanzas de la historia es que las marinas de guerra se han tenido que ir adaptando a los cambios ambientales. Hoy no es una excepción: tal es la magnitud de las transformaciones a nivel planetario, que se ha acuñado el término "nuevo orden mundial" para dar cuenta de las mismas.

No obstante, las Armadas seguirán teniendo una importancia capital en el tercer milenio; en primer lugar porque la superficie de los mares y océanos es aproximadamente dos veces y media mayor que la superficie terrestre, siendo las principales líneas de comunicación y tráfico, en especial del comercio mundial.

En segundo lugar, porque la escasez de recursos es una de las tendencias que se perfilan para el tercer milenio y el mar ofrece una alternativa ante esta situación; lo que necesariamente requiere la presencia física de los actores interesados en la efectiva explotación y comercialización de los recursos marinos, erigiéndose las marinas de guerra en la necesaria salvaguarda de las riquezas del mar territorial y de la zona económica exclusiva, ejerciendo vigilancia jurisdiccional y el resguardo del orden en tiempos de paz.

$\mathrm{Y}$, en tercer lugar, por el protagonismo político del mar, al estar presente en la mayoría de las situaciones de crisis y conflictos armados entre los Estados-nación.

\section{Control del mar}

En el pasado, el control del mar fue principalmente ejercido en actividades relacionadas con uno de los dos usos que puede tener el mar en tiempo de guerra. Esas actividades estuvieron dirigidas tanto al uso propiamente dicho del mar como a impedir su uso por parte del enemigo. El otro uso principal del mar en tiempo de guerra ha sido la proyección del poder militar desde el mar contra la costa, por medios que fueron desde el bombardeo naval hasta el apoyo a una invasión en gran escala.

Por supuesto, ésas no fueron las únicas funciones realizadas por las marinas en el devenir histórico. En mayor o menor grado han cumplido tareas de protección de recursos marítimos, ejercido la vigilancia jurisdiccional y el 
resguardo del orden en tiempos de paz. Del mismo modo, las marinas han sido siempre usadas como instrumentos directos de la política exterior de las naciones, y muchas de sus actividades, tanto en la paz como en la guerra, tuvieron un carácter más diplomático que militar.

La defensa marítima básica en los mares contiguos es la misión de casi los dos tercios de las marinas del mundo. Su objetivo es extender la defensa (y si se puede, también la potencialidad ofensiva) a las zonas marítimas adyacentes, haciendo aumentar así el costo de cualquier intrusión o interferencia indeseable. De ahí que "mares contiguos" sea una expresión más apropiada que "defensa costera" (Booth, 1980: 30).

\section{Clasificación de misiones}

El resultado de estas formidables mutaciones, de las que no escapa Estadonación alguno, es de tal complejidad que impone misiones de nuevo cuño a sus armadas. Tradicionalmente, las marinas de guerra trataban de ejercer el control de las comunicaciones marítimas. En el siglo xxI, las flotas se caracterizan por la diversidad de misiones.

Funciones marítimas tradicionales

- Influir en las percepciones de los posibles adversarios.

- Asegurar el control del mar (aspecto positivo: uso del mar; aspecto negativo: negación del uso del mar).

- Defensa de las líneas marítimas de comunicaciones.

- Proyección del poder naval contra la costa.

- Protección de instalaciones estratégicas.

- Apoyar a la política exterior del Estado.

Tareas nuevas para armadas nuevas

- Protección de aguas contiguas (intereses más allá de las costas), por ser fuente de alimentos, energía y materias primas.

- Obligar a cumplir la ley.

- Búsqueda y rescate / Salvaguarda de la vida humana en la mar.

- Protección física de las flotas pesqueras.

- Prevenir y combatir la contaminación.

- Combatir al crimen organizado y al terrorismo.

- Operaciones contra la piratería. 
- Operaciones de paz.

- Acciones de apoyo a Estados fallidos.

- Evacuación de la población civil.

- Investigaciones oceanográficas.

- Apoyo humanitario ante catástrofes naturales.

Vale la pena revisar el pensamiento europeo y estadounidense, con el objeto de dar cuenta de la evolución de las misiones reservadas a las armadas.

\section{a) Propuesta francesa}

El almirante Duval de la Marine Nationale francesa, citado por de Sault, sugiere la siguiente trilogía (de Sault, 1990: 95-97):

- Acción contra las fuerzas: es la antigua guerra de escuadras, ampliada ahora que la guerra marítima se desarrolla en tres dimensiones.

- Acción contra los intereses: es la antigua guerra de corso, ampliada como consecuencia de la "explosión" del tráfico marítimo.

- Acción contra la tierra: hasta el siglo XIX, no era posible prever más que golpes de manos, torpes para el adversario, pero incapaces de producir resultados decisivos; las flotas modernas pueden proyectarse sobre objetivos terrestres, incluso mediante la instalación de puertos artificiales.

A estas misiones tradicionales, pero renovadas, se añaden ahora tres nuevas:

- Manejo de la disuasión: a partir de la antigua teoría de la "flota en vida" (fleet in being) y que puede traducirse en: "hacer nada y al mismo tiempo estar listos para cualquier cosa"; sin embargo, hay evidentemente un cambio de naturaleza.

- Manejo de crisis: los marinos no son sólo marinos de guerra, su medio ambiente normal es como el de la extinta "guerra fría" o el de la "paz caliente".

- Protección de las zonas económicas exclusivas y de las instalaciones off shore: extensión de la tradicional misión de vigilancia y de defensa de las cercanías marítimas. 
A la que suma la tetralogía propuesta por el almirante Zumwalt, antiguo comandante de la us Navy:

- Disuasión: los marinos participan en la disuasión nuclear; ayer con los portaviones pertrechados con bombas nucleares, y hoy de manera central con los submarinos que no aseguran ninguna misión convencional. Ayer confinada al mecanografiado anticipado, a causa de la falta de precisión de sus misiles, los submarinos estratégicos adquieren progresivamente una capacidad contravalores y contrafuerzas con misiles más y más precisos y dotados de cabezas independientes MIRV ${ }^{3}$ (SSN23 soviético, Trident americano). Su casi invulnerabilidad no parece deber ponerse en entredicho en un futuro próximo, dado que se compensó el progreso de la detección con la prolongación del alcance de sus misiles (con la creciente proporción de sus zonas de patrullar) y el progreso de la discreción.

- Control de los mares: constituye la misión tradicional de control de las comunicaciones; las flotas más fuertes se van a esforzar en adquirir, conservar y explotar los bloqueos, que los más débiles se van a esforzar en retirar. Es la dimensión tradicional puramente naval de la guerra sobre el mar.

- Proyección de potencia: es la explotación del control de los mares contra la tierra. Puede tomar la forma de bombardeos por la artillería de los buques de línea en la zona costera (el acorazado New Jersey así usado en Corea y en Vietnam) o por la aviación embarcada (la incursión del general Doolittle contra Tokio en 1942) o a un nivel superior, operaciones anfibias: la II Guerra Mundial vio desembarcos gigantescos en África del Norte, Sicilia, Normandía, numerosas islas en el Pacífico; operaciones que fueron repetidas después de la guerra, a una escala evidentemente más modesta, en Inchón (1950) y en las Islas Malvinas (1982).

- Presencia: la diplomacia naval se ejerce ahora constantemente, bajo diversas formas, que van desde la clásica demostración de fuerza e intimidación,

3. MIRV, acrónimo inglés de multiple independently targetable reentry vehicle, que se traduce como vehículo de reentrada múltiple e independiente. Constituye una colección de armas nucleares introducidas en un único misil balístico intercontinental (ICBM, intercontinental ballistic missile) o un misil balístico intercontinental para submarinos (SLBM, submarine-launched ballistic missile). Con una cabeza nuclear MIRv, un solo misil puede golpear varios objetivos, o unos pocos objetivos con más fuerza. Por el contrario, una cabeza nuclear convencional tiene sólo una cabeza nuclear en un misil. Véase, Luttwak y Koehl, 1991. 
a la ocupación por la fuerza de islas o archipiélagos o el bombardeo como medida de represalia.

Estas tipologías son sensiblemente diferentes: se puede decir que las del almirante Duval son más "navales" que las del almirante Zumwalt, que tienen una tonalidad más "ínter armadas". Pero más allá de sus divergencias de aproximación, se complementan para subrayar la integración de la antigua estrategia naval en una estrategia global.

\section{b) Propuesta estadounidense (Global Security, 2009 b)}

La doctrina naval de Estados Unidos identifica operaciones en tiempos de paz y en tiempos de guerra.

\section{Operaciones en tiempos de paz}

Presencia y disuasión. La presencia de fuerzas navales puede evitar la confrontación y apoyar el cumplimiento de objetivos políticos, sin quebrantar la soberanía nacional. La armada puede consolidar esfuerzos diplomáticos por presencia ("showing the flag"), de una forma benigna como indicador general del interés y de la capacidad latente, y contribuyendo a prevenir conflictos emergentes. Alternativamente, las fuerzas navales se pueden desplegar como impedimento contra acciones específicas. Las marinas de guerra pueden también erigirse en un escudo ("shield") de los Estados, conforme a su petición, estableciendo una presencia en los mares territoriales, y tendiendo un manto protector sobre las áreas amenazadas. El uso del poder naval es menos invasor que el uso del poder militar basado en el componente militar terrestre.

Operaciones de paz. Este término se utiliza en un sentido genérico por cubrir una extensa gama de actividades, incluyendo la prevención de conflictos, la custodia y mantenimiento de la paz, aplicación e imposición de la paz, y la construcción de la paz. El uso de fuerzas navales en operaciones de paz complementará el accionar de las fuerzas terrestres y puede, generalmente, implicar un considerable menú de tareas. Estas tareas pueden incluir la observación y supervisión de los altos al fuego, la interposición entre las fuerzas navales de beligerantes y el establecimiento de zonas de retirada y evacuación, el abastecimiento de un lugar neutral para las negociaciones supervisadas, evitando que las fuerzas de los partes beligerantes violen acuerdos. 
Operaciones humanitarias. Las fuerzas navales se encuentran bien adaptadas para apoyar esfuerzos de la ayuda humanitaria que reduzcan el sufrimiento y el número de víctimas mortales, así como el daño a los bienes a causa de fenómenos naturales o desastres provocados por el hombre. Particularmente, las fuerzas navales son útiles para proporcionar un ambiente seguro y para permitir los esfuerzos de ayuda humanitaria de otras organizaciones. La preparación, flexibilidad, y movilidad de las fuerzas navales les permiten responder rápidamente a un desastre, particularmente si tienen infantes de marina $u$ otras tropas embarcadas. Las Armadas se pueden adaptar para reemplazar o complementar los esfuerzos de las naciones anfitrionas, autoridades civiles, o de las organizaciones no gubernamentales.

Protección de la libertad de navegación. Cuando las naciones presentan demandas sobre espacios marítimos en disputa, es probable que surjan obstáculos a la libertad de navegación. En tales casos, las fuerzas navales pueden ejercer la libertad de navegación o ejercitarse en las aguas bajo disputa (de conformidad con el derecho internacional reconocido). Las armadas pueden también proteger a la marina mercante.

Tareas marítimas policiales. Los desarrollos del derecho marítimo internacional de las tres últimas décadas, particularmente la extensión de la autoridad nacional más allá de las costas, ha dado lugar a una variedad de funciones de policía de baja intensidad. Estas funciones suelen involucrar a las fuerzas navales, así como guardacostas y/o agencias marítimas civiles. Se trata de un conjunto de funciones específicas que pueden incluir:

- Aplicación de las regulaciones de las pesquerías y de los acuerdos sobre la zona económica exclusiva (ZEE).

- Operaciones contra la piratería.

- Contraterrorismo.

- Interdicción de las drogas y del contrabando.

- Interdicción del comercio de esclavos o de la migración ilegal.

- Aplicación de regulaciones ambientales.

- Esquemas de control de tráfico y otras tareas marítimas de la gestión de tránsito.

Operaciones ambientales. Las fuerzas navales pueden también encargarse de responder ante los derramamientos de aceite y otros desastres ambientales. En estos casos, las Armadas pueden ser una valiosa fuente, al contar con personal 
entrenado y disciplinado, así como con el equipo idóneo, para enfrentar este tipo de accidentes. Estas operaciones son conducidas, a menudo, en concierto con o en apoyo de otras agencias gubernamentales, internacionales o privadas, cuyas misiones específicas incluyan respuestas a desastres.

Embargos/operaciones marítimas de interdicción (MIO). Las fuerzas navales pueden encargarse de hacer cumplir sanciones internacionalmente impuestas. La aplicación eficaz de sanciones puede requerir la coordinación sofisticada de operaciones militares en el mar y en el aire. Esto es especialmente cierto en áreas de conflicto armado o de alta tensión, donde la ausencia de reglas de enfrentamiento - comúnmente entendidas y aceptadas - puede aumentar significativamente los riesgos de las encargadas de hacer cumplir la ley. Las tareas asignadas pueden incluir la detención, inspección y desvío de las naves y aeronaves bajo sospecha, así como el establecimiento de una zona marítima de exclusión, para los buques mercantes y más de un actor en conflicto.

Operaciones de evacuación de no combatientes (NEO). Las operaciones de evacuación de no combatientes son conducidas para mover población civil de un área donde las condiciones de seguridad sufren un deterioro y ponen la vida humana en riesgo. Este tipo de operación es similar a una incursión anfibia, al basarse en la celeridad, la ocupación temporal de un objetivo y el retiro rápido después de completar la misión asignada. Durante una NEO, las reglas de enfrentamiento suelen limitar el uso de la fuerza al requerido para proteger a las personas evacuadas y a la fuerza de evacuación. Las fuerzas navales pueden tener una capacidad integral para lograr una NEO, prescindiendo de la ayuda de otras fuerzas. En caso contrario, los buques pueden proporcionar capacidades, protección y asegurar las zonas de espera cercanas para otras fuerzas.

\section{Operaciones en tiempo de guerra}

Durante el desarrollo de un conflicto armado, las actividades de la fuerza naval se dirigen normalmente a lograr el control del mar y proyectar poder en tierra.

Control del mar. El uso del mar requiere un grado de control. El control total del mar es raramente posible mientras un adversario continúe amenazando a fuerzas en el área. Por lo tanto, un grado de control del mar se establece normalmente dentro de un área señalada y por un periodo definido. El control del mar debe proporcionar la seguridad para las fuerzas, las instalaciones y 
las líneas de comunicación marítimas. Las grandes fuerzas navales utilizan un área para sus propios propósitos y pueden, usualmente, alcanzar y mantener suficiente control del mar; en tanto que fuerzas especializadas más pequeñas, especialistas y buques mercantes, requieren que el control del mar sea establecido por otras fuerzas o escoltas. La negación del uso del mar es un subconjunto del control del mar. Se alcanza la negación del uso del mar cuando las fuerzas navales evitan que una fuerza de oposición use el mar para sus propios propósitos. La negación del uso del mar se ejercita normalmente en un área dada y por un tiempo limitado.

Proyección del poder naval (Global Security, 2009a). Los conflictos en el mar raramente existen sin tener en cuenta una campaña terrestre o la búsqueda de objetivos territoriales. Incluso, cuando el componente marítimo es operacionalmente dominante, el último resultado en el teatro suele depender del éxito en tierra. Las fuerzas navales se deben preparar, a menudo, para funcionar en el ambiente litoral para proyectar la fuerza en tierra como parte de la participación de las operaciones conjuntas navales, aéreas, y terrestres. Las navales son normalmente las primeras en un área de crisis y pueden erigirse en la que permita un acceso conjunto de las fuerzas a la región. De manera tal que las Armadas contribuyen a las operaciones en tierra, apoyando directa o indirectamente a las operaciones terrestres.

Todo esto significa que, sin duda, la fuerza naval tiende a aumentar la importancia y la amplitud en sus tareas, porque posee los atributos de flexibilidad, gradualidad, versatilidad y simbolismo, que le permiten actuar en los ámbitos diplomático, marítimo y bélico sin mayores transformaciones. En definitiva, el poder naval seguirá brindando prestigio, seguridad e influencia en el concierto de las naciones a quien lo posea y tenga la voluntad política de utilizarlo en defensa del interés nacional.

En el caso de la Armada de México, su Ley Orgánica establece, entre otras, las siguientes atribuciones (Secretaría de Marina, 2009d):

I. Organizar, adiestrar, alistar, equipar y operar a las fuerzas que la constituyen para el cumplimiento de su misión y ejercicio de sus funciones;

II. Cooperar en el mantenimiento del orden constitucional del Estado Mexicano;

III. Realizar acciones para salvaguardar la soberanía y defender la integridad del territorio nacional en el mar territorial, zona marítimo-terrestre, islas, cayos, arrecifes, zócalos y plataforma continental; así como en aguas interiores, lacustres y ríos en sus partes navegables, incluyendo los espacios 
aéreos correspondientes, así como vigilar los derechos de soberanía en la zona económica exclusiva;

IV. Proteger el tráfico marítimo, fluvial y lacustre, en el área de jurisdicción federal y donde el Mando Supremo lo ordene y, en coordinación con otras autoridades competentes mediante convenios, establecer por instrucción del Mando Supremo las áreas de control al mismo, incluidos los respectivos espacios aéreos;

v. Salvaguardar la vida humana en la mar y en las aguas interiores, mediante operaciones de búsqueda, rescate y salvamento en las aguas marinas nacionales e internacionales y en todas aquellas en las que el Mando Supremo lo ordene;

vi. Proteger instalaciones estratégicas del país en su área de jurisdicción y donde el Mando Supremo lo ordene; ${ }^{4}$

vii. Auxiliar a la población en los casos y zonas de desastre o emergencia; aplicando los planes institucionales de protección civil, en coordinación con otras autoridades; ${ }^{5}$

viii. Proteger los recursos marítimos, fluviales y lacustres nacionales;

ix. Garantizar el cumplimiento del orden jurídico en las zonas marinas mexicanas por sí o coadyuvando con las autoridades competentes en el combate al terrorismo, contrabando, piratería en el mar, robo de embarcaciones pesqueras, artes de pesca o productos de ésta, tráfico ilegal de personas, armas, estupefacientes y psicotrópicos, en los términos de la legislación aplicable;

x. Realizar actividades de investigación científica, oceanográfica, meteorológica, biológica y de los recursos marítimos, actuando por sí o en colaboración con otras instituciones nacionales o extranjeras, o en coordinación con dependencias del Ejecutivo.

xi. Intervenir, sin perjuicio de las atribuciones de las dependencias del Ejecutivo, en la prevención y control de la contaminación marítima, así como vigilar y proteger el medio marino dentro del área de su responsabilidad, actuando por sí, o en colaboración con otras dependencias e instituciones nacionales o extranjeras.

4. En especial, las plataformas off shore de Petróleos Mexicanos (Pemex).

5. Lo que incluye, en los últimos años, la participación de la Armada en misiones más allá de las fronteras nacionales; se trata de la función diplomática del poder naval, en respuesta a contingencias naturales sufridas por países hermanos, por ejemplo ante los efectos del huracán Katrina (Estados Unidos) y el tsunami del océano Índico de 2004 (Indonesia, entre otros países afectados). 
De esta manera, el marco normativo consagra una amplitud y sobrecarga de misiones que van, desde la policía marítima, hasta las tradicionales de defensa y preservación de la soberanía nacional en el ámbito marítimo; 6 una combinación de funciones de guardacostas y de Armada, caracterizadas por la ausencia de condiciones reales para su efectivo cumplimiento, como se trata de demostrar a continuación.

\section{Consideraciones finales: contribución doctrinaria al desarrollo de la Armada de México}

Este amplio menú de misiones, responde a la calidad de México como país bi-oceánico (Secretaría de Marina, 2008: 3):

[situación] delicada, al colindar al Norte con los Estados Unidos de América [...] con el que se comparten amplias fronteras marítimas y terrestres que requieren de especial atención en materia de seguridad. Al Sur con países de Centroamérica que se encuentran en vías de desarrollo, con similares problemáticas sociales de migración, pobreza y desempleo, aunados a los problemas de narcotráfico, tráfico ilegal de personas y otras manifestaciones de la delincuencia organizada.

En este entorno regional, las condiciones de seguridad en el mar son amenazadas por actividades ilícitas realizadas principalmente por la delincuencia organizada, tales como el tráfico ilegal de drogas, de personas y de armas, actos de sabotaje de grupos subversivos y la piratería (Secretaría de Marina, 2008: 4).

Se trata de un conjunto de grandes desafíos e insuficientes capacidades navales para enfrentarlos, tal como se desprende de diversas fuentes reconocidas.

Para empezar, la propia Secretaría de Marina reconoce que para 2006 el poder naval nacional sólo tenía las capacidades como para proteger $53 \%$ de

6. Cabe señalar que, de conformidad con el acuerdo presidencial del 8 de septiembre de 1941, del entonces Presidente Manuel Ávila Camacho, se determina la jurisdicción de la Secretaría de Marina como: [...] una faja de territorio nacional, de 10 kilómetros de anchura a partir de la línea de marea media, así como las zonas que queden comprendidas entre dos líneas paralelas al lado y lado de las riberas de los ríos navegables, colocadas a cinco kilómetros a partir de ambas orillas y con una penetración río arriba, hasta donde se efectúen maniobras de navegación, limitadas en particular para cada río, con sujeción a las necesidades de las operaciones navales. 
los mares y litorales de México. Indicador por demás alarmante que impone como reto institucional desarrollar la capacidad operativa de los buques, aeronaves y unidades terrestres de la Armada de México, para mantener el control y dominio de los mares nacionales (Secretaría de Marina, 2008: 8 y 4 , respectivamente). ${ }^{7}$

A lo que se suma el inventario de medios navales de la prestigiosa publicación británica Jane's, especialista en el poder naval de las naciones. Por ejemplo, siguiendo a esta fuente, si se compara a la Armada de México con sus pares del resto de América Latina, salta a vista su situación de inferioridad con respecto a marinas de guerra tales como Argentina, Brasil, Chile, Colombia, Perú y Venezuela; si se tiene en cuenta que México carece de submarinos y opta por buques patrulleros (tendencia conocida como enanismo), en detrimento de las fragatas y destructores de vocación y condiciones marineras oceánicas.

La decisión de los propios marinos de sacrificar plataformas aptas para la proyección del poder naval en las zonas contigua y económica exclusiva, impiden a la armada de México ejercer el control y dominio del mar, proteger sus recursos naturales renovables y no renovables, así como combatir eficaz y eficientemente el tráfico de drogas por mar. Los patrulleros, como principal componente del poder naval mexicano, sólo le garantizan tender un manto protector sobre el mar territorial y parte de la zona contigua, es decir, el ejercicio de funciones policiales.

No deben extrañarnos las limitaciones a las que se enfrenta la Armada de México, cuando pretende proyectarse como instrumento de la política exterior, por ejemplo en ejercicios combinados con sus pares de terceros Estados. ${ }^{8}$

Con respecto al número de efectivos navales, México (Guevara, 2008a: 5) es similar a Brasil, único país en Latinoamérica en poseer un portaaviones y una flota de nueve fragatas, así como en tener el mayor número de submarinos, a excepción de Perú; por lo tanto, en México no existe una correspondencia o sano balance entre los medios navales y humanos a cargo de su operación.

7. En el mismo documento se asume el compromiso de alcanzar una cobertura de 84 por ciento como meta para 2012.

8. Así, recientemente, los 343 elementos de la Armada de México que participaron en los Ejercicios Navales UNITAS Gold 50-09, en aguas de Estados Unidos, enfrentaron limitaciones ante diversas fallas de los buques y helicópteros, así como falta de experiencia; al decir del propio Secretario de Marina, Almirante Francisco Saynez; véase Milenio, México, DF, viernes 21 de agosto de 2009, p. 22. 
Radiografía del poder naval en América Latina. Países seleccionados

\begin{tabular}{lrcccr}
\hline Países & Personal & Submarinos & Fragatas & Destructores & PV $\left(^{*}\right)$ \\
\hline Argentina & 17,000 & 3 & 9 & 4 & 15 \\
Bolivia & 4,400 & 0 & 0 & 0 & 0 \\
Brasil & 38,800 & 5 & 9 & 1 & 23 \\
Chile & 18,800 & 4 & 8 & 0 & 16 \\
Colombia & 12,100 & 4 & 4 & 0 & 93 \\
Ecuador & 2,700 & 2 & 1 & 0 & 0 \\
Guyana & 180 & 0 & 0 & 0 & 5 \\
Paraguay & 1,800 & 0 & 0 & 0 & 17 \\
México & 37,961 & 0 & 6 & 1 & 141 \\
Perú & 18,000 & 6 & 8 & 0 & 4 \\
Surinam & 240 & 0 & 0 & 0 & 8 \\
Uruguay & 3,850 & 0 & 2 & 0 & 10 \\
Venezuela & 9,500 & 2 & 6 & 0 & 0 \\
\hline
\end{tabular}

(*) PV (Patrol vessel, en castellano buque patrulla).

Fuentes: Jane's Sentinel Country Risk Assessments (2008) y Jane’s Sentinel Country Risk Assessments (2007); el subrayado es nuestro.

Para el caso mexicano, "The Military Balance" (The International Institute for Strategic Studies, 2009), da cuenta de un poder naval representado por un destructor, seis fragatas, y elevando a 171 las patrullas y buques costeros, a los que suma 19 buques logísticos y de apoyo, y tres buques de asalto anfibio. Tratándose del personal de la Armada, el International Institute for Strategic Studies (IISS), responsable de su publicación, considera que la plantilla de la Armada de México es de 55,961 efectivos, de los cuales 19,328 son infantes de marina y 1,250 están encuadrados en su aviación naval. Es decir, presenta una diferencia de 18,000 efectivos más que las cifras de personal reconocidas por Jane's; o, lo que es lo mismo, un número similar al total de marinos de Armadas tales como Argentina, Chile o Perú.

Ambas fuentes difieren de la propia Secretaría de Marina-Armada de México, como se desprende de la siguiente tabla, aunque el IISS se acerca más: 
Hacia un marco teórico y analítico del poder naval

Recursos humanos de las Fuerzas Armadas Mexicanas

\begin{tabular}{cccc}
\hline Año & Total & Sedena & Semar \\
\hline 2000 & 237,552 & 182,329 & 55,223 \\
2001 & 234,308 & 185,143 & 49,165 \\
2002 & 238,169 & 188,143 & 50,026 \\
2003 & 238,702 & 191,143 & 47,559 \\
2004 & 237,137 & 191,143 & 45,994 \\
2005 & 236,913 & 191,143 & 45,770 \\
2006 & 244,238 & 196,767 & 47,471 \\
2007 & 246,742 & 196,710 & 50,032 \\
2008 & 249,245 & 198,697 & 50,548 \\
\hline
\end{tabular}

Sedena: Secretaría de la Defensa Nacional; Semar: Secretaría de Marina/Armada de México. Fuente: Gobierno federal, 2008 a: 73; el subrayado es nuestro.

Los números de efectivos de la Armada de México llaman poderosamente la atención; y es que se puede constatar que a la llegada del gobierno de alternancia de primera generación encabezado por Vicente Fox Quesada, la Semar contaba con 55,223 elementos en actividad, y al finalizar su gestión, con 47,471, presentándose un comportamiento por demás irregular en la evolución de las cifras. Por el contrario, con el arribo al poder de Felipe de Jesús Calderón Hinojosa en 2006, se verifica una apuesta por el aumento del número de efectivos de la Semar, cerrando 2008 con un total de 50,548.

Esta apuesta presidencial por la Semar se constata en el reciente apoyo del titular del Poder Ejecutivo para la participación — ya citada - de la Armada mexicana en los ejercicios navales militares en Estados Unidos, denominados UNITAS 50-09; y avalados por el Senado por 66 votos a favor, 13 en contra y cero abstenciones. Ejercicios navales combinados, desarrollados del 19 de abril al 7 de mayo, con la integración de dos buques propios: la fragata clase Allende Arm Mina (F-214) y la patrulla oceánica clase Oaxaca Arm Oaxaca (PO-161), más un agrupamiento de infantería de marina (Gómez, 2009).

En cuanto a los medios, el sitio web de la Semar presenta los siguientes buques en existencia, distribuidos en dos grandes fuerzas navales: la del Golfo y la del Pacífico:

- La Fuerza Naval del Golfo (Secretaría de Marina, 2009a), integrada por una flotilla de destructores, compuesta por cuatro fragatas, un destructor y dos buques misileros; la flotilla de buques auxiliares, constituida por un buque 
de guerra anfibia, un buque multipropósito, y un buque auxiliar de transporte. A los que se suman las Fuerzas de Reacción Anfibia de Infantería de Marina, compuestas por: dos batallones anfibios, un batallón de comandos, un batallón de artillería, un batallón de embarcaciones y vehículos anfibios, un batallón de servicios y un escuadrón aeronaval de transporte y reconocimiento

- La Fuerza Naval del Pacífico (Manzanillo, Colima) (Secretaría de Marina, 2009c), que cuenta con fragatas Bronstein y destructores Gearing y Fletcher, más el buque de desembarco Papaolapan, el remolcador Chac y el transporte Nautla, en calidad de flotilla de buques auxiliares, más un escuadrón de helicópteros embarcados. Adicionalmente, contempla una Fuerza de Reacción Anfibia, con dos batallones anfibios de infantería de marina, tres compañías de vehículos de asalto anfibio, un batallón de comandos anfibios, un batallón de artillería de infantería de marina, una compañía de reconocimiento anfibio y un batallón de servicios, más un escuadrón de ala fija.

De acuerdo con la propia Semar, la Armada de México cuenta con seis fragatas y tres destructores, o sea, dos más de los que se consignan en Jane's (2007) y The Military Balance (2009). Como quiera que sea, la obsolescencia es su común denominador, si se tiene en cuenta que los destructores (ex US Navy) fueron comisionados durante la segunda conflagración mundial, y que uno de ellos, el destructor escolta "Manuel Azueta" (ex USN Clase Edsall) es utilizado exclusivamente para entrenamiento; en tanto las fragatas Clase Allende (ex USN Clase Knox) más modernas son de la década de los setenta del siglo pasado (Guevara, 2008 b: 19).

En rigor, la flota mexicana constituye una fuerza naval costera o de defensa territorial costera (Booth, 1980; Till, 2003), encargada de asegurar el control efectivo de sus aguas territoriales y la vigilancia parcial o limitada de su zona económica exclusiva; privilegiándose como instrumentos la aviación de patrullaje basada en tierra, y un gran número de navíos ligeros de superficie, incluyendo patrulleros lanza misiles. Esto explica que el perfil de la Armada de México sea similar al de un servicio de guardacostas o prefectura naval, al carecer de las capacidades de proyectar el poder naval y garantizar la preservación de la zona económica exclusiva. ${ }^{9}$

9. De ahí que el mayor número de operaciones y ejercicios combinados que, desde la década de los noventa desarrolla la Armada de México, tenga como contraparte al us Coast Guard. 
Esto es así, a la luz del propio marco constitucional mexicano, el cual antepone la seguridad interior a la defensa exterior de la federación (Artículo 89, fracción vi de la Constitución General de la República); lo que significa que la preservación de la tranquilidad y el orden público, así como el mantenimiento de la paz social, constituyen las prioridades para el constituyente permanente.

Todo lo cual se traduce en la incapacidad de la Armada de México para cumplir con las siguientes funciones marítimas tradicionales: ejercer influencia en las percepciones de los posibles adversarios, asegurar el control del mar y apoyar a la política exterior.

Mientras que sí se encuentra en condiciones de garantizar, de manera parcial o limitada, las funciones históricas de: defender las líneas marítimas de comunicaciones (en el mar territorial y parte de la zona contigua), proyectar el poder naval contra la costa y proteger instalaciones estratégicas.

Tratándose de tareas nuevas para armadas nuevas, el poder naval mexicano puede: obligar a cumplir la ley en el mar territorial y parcialmente en la zona contigua; llevar a cabo misiones de búsqueda y rescate (salvaguarda de la vida humana en la mar); prevenir y combatir la contaminación; intervenir en situaciones de desastres naturales y socio-organizativos; evacuar a la población civil y participar en misiones humanitarias, ante catástrofes sufridas por países hermanos

Por el contrario, la Armada mexicana no cuenta con las capacidades para combatir de manera frontal y eficiente al crimen organizado y al terrorismo; participar en operaciones de paz; ni intervenir en acciones de apoyo a Estados fallidos.

Debido a sus limitados medios, cabe preguntarse sobre el destino y las tareas de una plantilla de recursos humanos superior a cualquier Armada latinoamericana, incluyendo la brasileña, a la sazón la más poderosa de la región. Tal vez valdría la pena especular para llegar a las siguientes conclusiones:

a) La existencia de un problema de diseño institucional, al no existir en México una secretaría o ministerio único de despacho en materia de Defensa Nacional; efectivamente, coexisten la Secretaría de la Defensa Nacional (Sedena), que integra al Ejército y a la Fuerza Aérea, a la par que la Secretaría de MarinaArmada de México (Semar); cuyo resultado es la confusión entre la dimensión política y la técnica, ya que en el caso de la Semar, son los propios marinos quienes determinan, diseñan y ejecutan la política naval del Estado mexicano, con absoluta autonomía y ausencia de controles reales y efectivos. 
Dicho en otros términos, en México los militares y marinos gozan de un elevado grado de autonomía, puesto que los únicos mecanismos de control son ejercidos por el Presidente de la República en su calidad de Comandante Supremo de las Fuerzas Armadas (Artículo 89, fracción vi de la Constitución Política de los Estados Unidos Mexicanos) y el Congreso de la Unión, al someterse a su aprobación el Presupuesto de Egresos de la Federación y el pliego de ascensos de los oficiales superiores de las tres fuerzas.

La debilidad no sólo se traduce en el déficit de un control efectivo, sino también en la ausencia de una verdadera rendición de cuentas de los uniformados; cuyo significado es una especie de "caja negra": tanto la Sedena como la Semar se mantienen al margen de cualquier intervención del poder político, ya que los militares y marinos son "arquitectos de su propio destino", al tomar decisiones sobre la política de defensa y la política naval, respectivamente.

A diferencia de países con tradición democrática o en transición a la democracia, donde las Fuerzas Armadas se conciben como instrumentos de ejecución y son los civiles los que fijan y determinan estas políticas sectoriales, en México los titulares de ambas secretarías de despacho son militares en servicio y el poder político no tiene injerencia alguna sobre las mismas.

La coexistencia de dos secretarías también se traduce en una duplicidad de funciones, dispendio de recursos y reproducción de una burocracia sobredimensionada, puesto que prácticamente la totalidad del personal administrativo de la Semar son marinos en servicio o actividad, es decir, marinos que "navegan" detrás de los escritorios; porque la Semar no deja de ser una dependencia administrativa del Poder Ejecutivo de la Federación, sometida a reglas burocráticas establecidas normativamente, que demanda recursos humanos para su cumplimiento.

En este marco, llama la atención el elevado número de oficiales superiores que, para 2008 era de: 19 almirantes, 69 vicealmirantes y 133 contraalmirantes; lo que, sin duda, distorsiona la pirámide jerárquica o escalafón (Gobierno Federal, 2008b). ${ }^{10}$

b) la consolidación de un cuerpo de infantería de marina (IM) sobredimensionado, ya que sus elementos tienen un peso equivalente a casi la tercera parte

10. A lo que hay que sumar 304 capitanes de navío en servicio en 2008 , equivalentes a la jerarquía de coronel y, por ende, dependientes de la facultad del Senado de la Nación para la obtención del grado; al autorizar la Cámara Alta las promociones de capitán de fragata a navío. 
del total de efectivos de la Semar. ${ }^{11}$ Esta sobreestimación de la IM se refleja también en la adquisición de buques de asalto anfibio, como los dos Clase Papaolapan (ex USN Newport Class) clasificados como LST, ${ }^{12}$ aptos para atender desastres naturales y socio-organizativos, ayuda humanitaria y combate a la delincuencia organizada en el litoral marítimo.

Precisamente, el desarrollo de la IM es consustancial a una armada costera, de proyección del poder naval hacia la franja costera y para desempeñar misiones y funciones de naturaleza policial. Pero, adicionalmente, la presencia terrestre de la Armada estriba en el hecho de que "la influencia sobre los asuntos del Estado se dirime en tierra y no en alta mar [...] el poder de fuego de las fuerzas anfibias es parte de la proyección de las armadas en los asuntos internos", es decir, en la influencia sobre la política interna del país (Sohr, 1990: 124)

En conclusión, el poder naval mexicano no guarda correspondencia con la capacidad de generación de riqueza de la economía nacional, ni con las condiciones geopoliticas, de configuración territorial y de extensión de su zona económica exclusiva. Antes bien, la tradicional limitación de las aspiraciones de México en el mar, han relegado a la Armada a un segundo plano.

Además, se trata del costo que pagarían los marinos en beneficio del componente terrestre del poder militar, sobre las espaldas del cual descansa la lucha contra el narcotráfico. Al más alto nivel de conducción política la decisión de comprometer directamente a los militares en el combate a la principal amenaza a la seguridad nacional mexicana, trae aparejado un incremento de recursos financieros destinados a la Sedena en detrimento de la Semar (Gobierno Federal, 2009). ${ }^{13}$

11. Hace casi dos décadas, un especialista llamaba la atención sobre "la llamativa alta proporción de la infantería de marina en América Latina, considerando que la mayor parte de los conflictos previsibles son terrestres y es improbable un enfrentamiento en ultramar [...] uno de cada cuatro integrantes de la armada, en circunstancias que los británicos tiene uno por cada diez [...] las flotas no se contentan con dominar el mar y quieren intervenir, al menos, en las playas. Pero ello no explica, desde el punto de vista de la lógica militar, las enormes dimensiones de las infanterías de marina latinoamericanas" (Sohr, 1990: 124).

12. LST, acrónimo inglés, cuyo significado es Landing Ship Tanks.

13. El presupuesto de la Sedena se incrementó de 32,200 millones de pesos en 2007, a 34,861 millones durante 2008 y a 43,623 millones en 2009. Por su parte, las asignaciones a la Semar alcanzaron los 10,951 millones de pesos en 2007 y los 13,382 millones en 2008, para cerrar con 16,059 millones en 2009. No obstante estos aumentos, la diferencia a favor de la Sedena es sustancial. 
A esta última, la Federación le reserva un papel secundario en el enfrentamiento al crimen organizado; lo cual resulta paradójico si se tiene en cuenta que los mayores flujos de drogas, estupefacientes y sustancias psicotrópicas circulan por la vía marítima. (Organización de los Estados Americanos, 2003: 4; Organización de Naciones Unidas, 2009: 75).

En los albores del tercer milenio, México debería sentar las bases de desarrollo de fuerzas navales con relativa capacidad de proyección, para estar en condiciones reales de velar por la preservación de lo que el Derecho del Mar le reconoce en calidad de estado ribereño: lo que se traduce en apostar por el desarrollo de una Armada contigua.

En definitiva, la realidad y los propios intereses marítimos, obligan a considerar la reforma naval como un componente insoslayable de la reforma del Estado en México; mediante el desarrollo de un poder naval balanceado que responda y se encuentre a la altura de los retos del presente pero, fundamentalmente, del futuro. miv

\section{Bibliografía}

Aguayo Joaquín Eduardo y Roberto Trápaga, "México y sus recursos minerales en la zona económica exclusiva”, en Aguayo, Joaquín Eduardo y Roberto Trápaga, Geodinámica de México y minerales del mar, México, Fondo de Cultura Económica, 1996. Disponible en: http://bibliotecadigital.ilce.edu. $\mathrm{mx} /$ sites/ciencia/volumen3/ciencia3/141/htm/sec_10.htm

Blanco Núñez, José María, “Ferrol: poder marítimo, poder naval”, MILITARIA. Revista de Cultura Militar, núm. 8, Servicio de Publicaciones UCM, Madrid, 1996. Disponible en: http://revistas.ucm.es/amm/02148765/articulos/ MILT9696110039A.PDF. Fecha de consulta: 05 de marzo de 2009.

Booth, Ken, Las Armadas y la política exterior, Instituto de Publicaciones Navales, Buenos Aires, 1980.

De Sault, Olivier, “Qu'est-ce qu'une marine?”, Strategique, núm. 48, Fondation pour les Estudes de Defense Nationale, La stratégie maritime, París, 1990.

George, James L., Los problemas del poder marítimo en tanto nos acercamos al siglo XXI, Instituto de Publicaciones Navales, Buenos Aires, 1980.

Global Security (2009a), Maritime Power Projection. Disponible en: http:// www.globalsecurity.org/military/ops/maritime-power-projection.htm. Fecha de consulta: 08 de mayo de 2009. 
- (2009b), Sea Power. Disponible en: http://www.globalsecurity.org/military/ops/sea.htm. Fecha de consulta: 08 de mayo de 2009.

Gobierno Federal, Anexo Estadístico del Segundo Informe de Gobierno, 2008a

p. 73. Disponible en: http://www.informe.gob.mx/anexo_estadistico/ PDF/ESTADISTICAS_NACIONALES/ESTADO_DE_DERECHO_Y_ SEGURIDAD/2_1.pdf. Fecha de consulta: 29 de abril de 2009.

Gobierno Federal, Presupuesto de Egresos de la Federación 2008 - Analítico de Plazas Ramo 13: Secretaría de Marina México, $1^{\circ}$ de enero de 2008, p. 2, más 304 capitanes de navío, 2008b. Disponible en: http://www.apartados.hacienda.gob.mx/presupuesto/temas/pef/2008/temas/tomos/13/ r13_app.pdf. Fecha de consulta: 29 de abril de 2009.

——, Presupuesto de Egresos de la Federación para el Ejercicio Fiscal 2009, 2009. Disponible en: http://www.cddhcu.gob.mx/LeyesBiblio/ref/pef_2009/ PEF_2009_orig_28nov08.pdf. Fecha de consulta: 29 de abril de 2009. Gómez, Ricardo, "La Armada acudirá a ejercicio multinacional", El Universal, México, DF, miércoles 15 de abril de 2009. Disponible en: http://www. eluniversal.com.mx/nacion/167189.html.

Gorshkov, Serguéi, Las fuerzas navales (su historia y su presente), Editorial Progreso, Moscú, 1980.

Guevara, Íñigo, "A New Mexican Wave”, International Fleet Review, HPC Publishing, East Sussex, Gran Bretaña, 2008a.

-_, "Mexico's Fleet Desires a Full-Throttle Future", International Fleet Review, HPC Publishing, East Sussex, Gran Bretaña, febrero, 2008b.

Guitton, Jean, El pensamiento y la guerra, Instituto de Publicaciones Navales, Buenos Aires, 1972.

Hagedorn Hitschfeld, Jorge, "Armada expedicionaria, una visión realista del futuro", Revista de Marina, Armada de Chile, 2008, núm. 1. Disponible en: http://www.centronaval.org.ar/boletin/bcn/BCN820/820estelas02.pdf Howard, Michael, "El concepto del poder aéreo (una evaluación histórica)", Air \& Space Power Journal, 1996. Disponible en: http://www.airpower. maxwell.af.mil/apjinternational/apj-s/1996/2trimes96/howard.html. Fecha de consulta: 30 de abril de 2009.

Jane's Sentinel Country Risk Assessments, Central America and the Caribbean, 2007, Jane's Information Group Limited, Gran Bretaña, vol. 21, Surrey. - - South America, 2008, Jane's Information Group Limited, Surrey, Gran Bretaña, vol. 22.

Lacaste, P., Stratégie Navale, Nathan, París, 1981. 
Luttwak, Edward y Stuart L. Koehl, The Dictionary of Modern War (A guide to the ideas, institutions and weapons of the modern military power vocabulary), Gramercy Books, Nueva York, 1991.

Mahan, Alfred Thayer, Influencia del poder naval en la historia, Editorial Partenón, Buenos Aires, 1946.

- - The Influence of Sea Power upon History 1660-1805, Prentice-Hall Inc., Englewood Cliffs, New Jersey, 1980.

Moloeznik, Marcos Pablo, "La naturaleza de un instrumento militar atípico: las fuerzas armadas mexicanas", Fuerzas Armadas y Sociedad, año 19, núm. 1, pp. 203-206, 2005. Disponible en: http://www.fasoc.cl/files/articulo/ ART43621ecb1574e.pdf.

Navy Records, Bibliografía de Sir Julian Corbet, 2009. Disponible en: http:// www.navyrecords.org.uk/figcorbett.htm. Fecha de consulta: 11 de marzo de 2009.

Organización de los Estados Americanos, Comisión Interamericana para el Control del Abuso de Drogas, "Estudio hemisférico del narcotráfico marítimo", Washington, DC, 2003. Disponible en: http://www.cicad.oas. org/Reduccion_Oferta/ESP/Recursos/Maritime/Report_XXXIV_esp.pdf. Fecha de consulta: 20 de agosto de 2009.

Organización de las Naciones Unidas, Junta Internacional de Fiscalización de Estupefacientes, Informe 2008, Nueva York, 2009. Disponible en: http://www.cinu.org.mx/prensa/especiales/2009/informeanual/docs/ informeanual.pdf.

Organización de las Naciones Unidas, Convención de las Naciones Unidas sobre el Derecho del Mar, 1982. Disponible en: http://www.un.org/Depts/los/ convention_agreements/texts/unclos/convemar_es.pdf. Fecha de consulta: 17 de abril de 2009.

Potter, E. B. y C. Nimitz, Sea Power: A Naval History, Prentice-Hall, New Jersey, 1960.

Pertusio, Roberto L., Una marina de guerra. ¿Para hacer qué?, Instituto de Publicaciones Navales, Buenos Aires, 1990.

Ranft, Bryan, "Sir Julian Corbett", en Till, Geoffrey, Craig Symonds, Bryant Ranft, Barry Hunt, John Hattendorf, Stephen Roskill, Peter Nailor y Richard Hill (1984), Estrategia marítima y la era nuclear, Instituto de Publicaciones Navales, Buenos Aires, 1984. 
Secretaría de Marina, "Decreto por el que se aprueba el Programa Sectorial de Marina 2007-2012", Diario Oficial de la Federación, tomo DCLII, núm. 14, México, lunes 21 de enero de 2008, cuarta sección.

Secretaría de Marina-Armada de México, Fuerza Naval del Golfo, 2009a. Disponible en: http://www.semar.gob.mx/fuerzas/golfo/fuernavgo.htm. Fecha de consulta: 05 de mayo de 2009.

——, Historia de la Armada, 2009b. Disponible en: http://www.semar.gob. $\mathrm{mx} /$ historia/index.html. Fecha de consulta: 29 de abril de 2009.

_- La Fuerza Naval del Pacífico, 2009c. Disponible en: http://www.semar. gob.mx/fuerzas/pacifico/fuernavpa.html. Fecha de consulta: 05 de mayo de 2009.

Secretaría de Marina-Armada de México, Marco Jurídico, 2009d. Disponible en: http://www.semar.gob.mx/juridico/misiatri.htm. Fecha de consulta: 08 de mayo de 2009.

Simpson, Mitchell B., Guerra, estrategia y poder marítimo, Instituto de Publicaciones Navales, Buenos Aires, 1983.

Sohr, Raúl, Para entender la guerra, Alianza Editorial-Conaculta, México, 1990.

Sprout Tuttle, Margaret (1968) "Mahan: evangelista del poder naval", en Earle Mead, Edward, Craig Gordon A. y Gilbert Félix, Creadores de la estrategia moderna (El pensamiento militar desde Maquiavelo a Hitler), Círculo Militar, Biblioteca del Oficial, tomo III, capítulo 17, Buenos Aires.

Tangredi, Sam J. (ed.), Globalization and Maritime Power, Institute for National Strategic Studies/National Defense University, Washington, DC, 2002.

Till, Geoffrey, "Can Small Navies Stay Affloat?", Jane's Navy International, Jane's Information Group Limited, Surrey, Gran Bretaña, 2003.

Till, Geoffrey, Craig Symonds, Bryant Ranft, Barry Hunt, John Hattendorf, Stephen Roskill, Peter Nailor y Richard Hill, Estrategia marítima y la era nuclear, Instituto de Publicaciones Navales, Buenos Aires, 1984.

The International Institute for Strategic Studies (2009), The Military Balance 2009, Londres. Disponible en: http://www.iiss.org/publications/militarybalance/.

Vego, Milan N., "On Naval Power”, Joint Force Quarterly, núm. 50, 2008, Focus on Naval Power, National Defense University, Washington, DC. 